\title{
Helicobacter spp. in Necropsied Southern Sea Otters (Enhydra lutris nereis) Is Associated With Gastric Ulcers and Sensitive to Multiple Antibiotics
}

\author{
Francesca I. Batac ${ }^{1,2 *}$, Melissa A. Miller, ${ }^{1,3}$, Megan E. Moriarty ${ }^{3}$, Zeli Shen ${ }^{4}$, \\ James G. Fox ${ }^{4}$ and Karen M. Ottemann ${ }^{2}$
}

${ }^{1}$ California Department of Fish and Wildlife - Office of Spill Prevention and Response, Marine Wildlife Veterinary Care and Research Center, Santa Cruz, CA, United States, ${ }^{2}$ Department of Microbiology and Environmental Toxicology, University of California, Santa Cruz, Santa Cruz, CA, United States, ${ }^{3}$ Karen C. Drayer Wildlife Health Center, One Health Institute, University of California, Davis, Davis, CA, United States, ${ }^{4}$ Division of Comparative Medicine, Massachusetts Institute of Technology, Cambridge, MA, United States

OPEN ACCESS

Edited by:

Stephen Raverty,

Animal Health Center, Canada

Reviewed by:

Grażyna Gościniak,

Wroclaw Medical University, Poland

Heriberto Fernandez,

Austral University of Chile, Chile

Thomas Blanchard,

University of Maryland, Baltimore,

United States

Pamela Tuomi,

Alaska SeaLife Center, United States

*Correspondence:

Francesca I. Batac

francesca.batac@wildlife.ca.gov

Specialty section:

This article was submitted to

Marine Megafauna,

a section of the journal

Frontiers in Marine Science

Received: 23 March 2020

Accepted: 12 May 2020

Published: 10 June 2020

Citation:

Batac Fl, Miller MA, Moriarty ME, Shen Z, Fox JG and Ottemann KM (2020) Helicobacter spp. in Necropsied Southern Sea Otters (Enhydra lutris nereis) Is Associated With Gastric Ulcers and Sensitive

to Multiple Antibiotics.

Front. Mar. Sci. 7:413.

doi: 10.3389/fmars.2020.00413
Southern sea otters (Enhydra lutris nereis) are threatened marine mustelids that commonly have gastric ulcers with secondary hemorrhage (melena) as a contributing cause of death. Although Helicobacter spp. infections are known to cause gastric ulcers and gastritis in humans and ferrets, it is unknown if the sea otter bacterium, $H$. enhydrae sp. nov., causes similar gastric pathology. Determining whether Helicobacter detection is associated with sea otter gastric pathology is the first step toward using this information to expedite diagnosis and treatment. We investigated the proportion of Helicobacter infections in 46 necropsied southern sea otters via quantitative realtime polymerase chain reaction (qPCR) of the $16 \mathrm{~S}$ rRNA gene. Helicobacter DNA was detected in fresh-frozen and formalin-fixed gastric body and pyloric tissues using Helicobacter genus-specific 16S rRNA primers. Data from gross necropsy and histopathology were analyzed for associations between Helicobacter detection via qPCR and presence/absence of gastric pathology. ETEST ${ }^{\circledR}$ gradient strips were utilized to investigate antimicrobial minimum inhibitory concentrations for $\mathrm{H}$. enhydrae isolates. Helicobacter spp. were detected in the gastric tissue of $85 \%$ of sea otters in this study. Fresh-frozen samples were more commonly Helicobacter qPCR-positive than formalin-fixed tissue, indicating variable sensitivity of detection in relation to postnecropsy tissue processing methods. Diagnosis of gastric ulcers at necropsy was significantly associated with Helicobacter qPCR detection in gastric mucosa ( $P=0.005)$, while age, sex, presence of melena, shark trauma, and protozoal infection were not associated $(P>0.1)$. Helicobacter enhydrae isolates were sensitive to clarithromycin and tetracycline in vitro at physiologically relevant concentrations. Overall, this work suggests that Helicobacter spp. might be commonly found in southern sea otters, particularly those with ulcers, and that $H$. enhydrae can be treated with several commonly used anti-Helicobacter therapies.

Keywords: antimicrobial sensitivity test, gastric ulcer, Helicobacter enhydrae, Helicobacter detection, quantitative PCR, sea otter 


\section{INTRODUCTION}

Sea otters (Enhydra lutris) are one of the smallest marine mammals, but are the heaviest member of the family Mustelidae, with a unique metabolism. These animals have twice the metabolic rate of other marine mammals and 2-3 times the rate of a comparably sized terrestrial animal; as a result, they require food consumption equivalent to $25 \%$ of their body weight each day (Iversen, 1972; Morrison et al., 1974; Yeates et al., 2007). With such high caloric demands, gastrointestinal health is critical for the well-being of sea otters. Bacteria in the Helicobacter genus are a highly influential component of overall gastric health. In humans, gastric infection by the bacterium Helicobacter pylori is found in up to $50 \%$ of people worldwide and is associated with gastritis, gastric ulcers, and gastric cancers (Marshall and Warren, 1984; Cover and Blaser, 1996; Zamani et al., 2018). Mammalian infections with non-pylori Helicobacter species have been shown to co-occur with gastritis, gastric ulcer, and/or gastric adenocarcinoma development, specifically, $\mathrm{H}$. cetorum in marine mammals and H. mustelae in ferrets (Fox et al., 1990, 1997; Harper et al., 2002, 2003).

A novel Helicobacter species, $H$. enhydrae sp. nov. (strain MIT 01-6242, GenBank No. AY203901), was isolated and characterized from the gastric mucosa of southern sea otters (Enhydra lutris nereis) (Shen et al., 2017). Electron microscopy and silver stains showed a slightly curved bacterial rod with lateral flagellae (Shen et al., 2017). This novel bacterium was catalase- and oxidase-positive and urease-negative with 65 genes homologous to virulence factors in related genera (Shen et al., 2017). Based on targeted Helicobacter spp.-specific 16S rRNA polymerase chain reaction (PCR), $58 \%$ of 31 tested sea otters were positive for Helicobacter DNA in gastric mucosa collected at necropsy (Fox et al., 1988; Shen et al., 2017). The H. enhydrae sp. nov. strain demonstrated close phylogeny to $H$. mustelae from domestic ferrets (Mustela putorius furo), based on Helicobacter $16 \mathrm{~S}$ and $23 \mathrm{~S}$ rRNA gene sequences (Shen et al., 2017). A prior study found, but did not characterize, two southern sea otter Helicobacter isolates (MIT 01-5923 and MIT 01-5924) that shared phylogeny with Helicobacter spp. from a California sea lion (Zalophus californianus) (MIT 02-5519-C) and a harp seal (Phoca groenlandica) (MIT 01-5529-A) (Harper et al., 2003). Sea otter microbiome analyses had also identified 11 Helicobacter spp. amplicon sequence variants from gingival and rectal swabs (Dudek, 2018).

As part of a large retrospective study of southern sea otter mortality patterns from 1998 to 2012, gastric ulcers and melena (i.e., upper gastrointestinal bleeding) were identified as a contributing cause of death (COD) for $42.3 \%$ (237/560) of sea otters examined via necropsy and histopathology (Miller et al., 2017). While gastric ulcers have been previously reported as a cause of sea otter mortality (Kreuder et al., 2003; Williams et al., 2018; Mansour-Ghanaei et al., 2019), the high prevalence of this condition was not appreciated until this comprehensive study. In prior reports, gastric ulcers and melena in sea otters have often been attributed to captivity-associated stress or were considered a sequela to petroleum exposure (Lipscomb et al., 1993; Loughlin, 1994; Williams and Davis, 1995; Reimer and Lipscomb, 1998).
Other potential causes of gastric ulcers and melena in sea otters have not been systematically assessed, such as Helicobacter spp.associated gastric infections. In a closely related mustelid, the ferret, H. mustelae, is strongly linked to gastric ulcers (Fox et al., 1988, 1990, 1991a; Batchelder et al., 1996).

As a federally listed threatened species with population estimates of just over 2,962 animals (Hatfield et al., 2019), it is important to determine whether gastric pathology in southern sea otters may be associated with Helicobacter infections. As a first step, we screened southern sea otter fresh-frozen and formalinfixed gastric tissues for the presence of Helicobacter spp. DNA via quantitative real-time PCR (qPCR) using Helicobacter 16S rRNA primers. Demographic, gross postmortem, and histology data were evaluated to measure associations with Helicobacter detection via $\mathrm{qPCR}$. As a secondary objective, we assessed the antibiotic efficacy of $H$. enhydrae in vitro to antibiotics tested against $H$. pylori.

\section{MATERIALS AND METHODS}

\section{Tissue Collection and Processing Procedures}

Gastric samples were from fresh, necropsied sea otters collected by staff of the California Department of Fish and Wildlife (CDFW) in the course of their duties as an official or state employee. All work was performed in accordance with Section 109(h) of U.S. Marine Mammal Protection Act (MMPA), U.S. Fish and Wildlife Service (Service) regulations implementing the MMPA at 50 CFR 18.22(a), and in accordance with Service regulations implementing the US Endangered Species Act at 50 CFR 17.21(c)(3).

Necropsy and histology sampling protocols for the 46 enrolled sea otter carcasses were performed as previously described (Kreuder et al., 2003). In brief, opportunistic sampling of minimally decomposed sea otters of various age classes and sexes was performed; the sea otters were refrigerated at 7$10^{\circ} \mathrm{C}$ and examined at CDFW-Marine Wildlife Veterinary Care and Research Center (CDFW-MWVCRC) (Santa Cruz, CA, United States) between 2015 and 2017. During necropsy, the stomach and proximal duodenum were opened lengthwise; and the mucosa was visually inspected for erosions, ulcers, and melena. Gastric lesion locations and relative severities were documented via summary notes and, in some cases, photographs. Two sets of adjacent gastric body and pylorus samples were collected using sterile scalpel blades. One set was placed in cryovials and then frozen in a $-80^{\circ} \mathrm{C}$ freezer until processed for DNA purification. The other set was placed in 10\% buffered formalin for fixation, tissue processing, and microscopic examination. The formalin-fixed gastric mucosa was trimmed and submitted to the UC Davis Veterinary Medical Teaching Hospital for paraffin embedding, cutting of $5 \mu \mathrm{m}$ thick sections, and hematoxylin and eosin (H\&E) staining for examination by light microscopy.

Gastric erosions were defined as foci of denuded surface epithelium and underlying lamina propria where tissue loss did not extend into the muscularis mucosa; ulcers penetrated more 
deeply and extended into or through the muscularis mucosa (Tarnawski et al., 1995). Both forms of gastric lesions were combined, and the pooled dataset was referred to as "ulcers" to facilitate analyses.

\section{DNA Purification From Gastric Tissues and qPCR Assay}

DNeasy Blood and Tissue Kit (Qiagen) and QIAamp DNA FFPE Tissue Kit (Qiagen) were used for DNA extraction of the fresh-frozen ("frozen") gastric body and pylorus samples (25 mg/sample) and the formalin-fixed, paraffin-embedded ("fixed") samples (60-80 $\mu \mathrm{m} /$ sample), respectively, per Qiagen's extraction protocols. Primer sequences (forward primer 116F $5^{\prime}$ AGT AAT GCA TAG GTT ATG TGC CCT- $3^{\prime}$ and reverse primer 237R 5'-CAA GCT GAT AGG ACA TAG GCT GAT-3') were constructed by Geneious R10.1.3 (Biomatters Ltd.) and amplified a 117-122 bp product of the 16s rRNA gene from the Helicobacter genus. qPCR was performed on the CFX Connect ${ }^{\mathrm{TM}}$ Thermal Cycler (Bio-Rad Laboratories, Inc., United States) using a $25 \mu \mathrm{m}$ primer concentration and a $20 \mu \mathrm{L}$ reaction mix final volume.

The following qPCR conditions were specific for SensiMix ${ }^{\mathrm{TM}}$ SYBR $^{\circledR}$ No-ROX (Bioline) and the primer sequences: 1 cycle of polymerase activation at $95^{\circ} \mathrm{C}$ for $10 \mathrm{~min}$, then 40 cycles of denaturing at $95^{\circ} \mathrm{C}$ for $15 \mathrm{~s}$, annealing at $57^{\circ} \mathrm{C}$ for $15 \mathrm{~s}$, and elongation at $72^{\circ} \mathrm{C}$ for $15 \mathrm{~s}$. The following were used as qPCR controls: no-template control (NTC) with nuclease-free water, negative control with Escherichia coli DH10B genomic DNA, positive control with $H$. enhydrae genomic DNA, isolated as above. All frozen and fixed gastric samples had 2-4 technical replicates (Supplementary Tables S1, S2). For the frozen samples $(n=92)$, we were able to obtain separate gastric body and pylorus for all 46 sea otters (Table 1). For the fixed samples $(n=59)$, gastric body and pylorus samples were either on separate paraffin blocks (30/59) or on a single block (29/59) (Table 1).

The quantification cycle $(\mathrm{Cq})$ is the cycle $(1-40$, with 40 being the lowest value) in which the intensity of the fluorogenicmarked amplicons is higher than background noise. Serial dilutions of purified $H$. enhydrae genomic DNA, including 89, $8.9,8.9 \times 10^{-2}, 8.9 \times 10^{-4}$, and $8.9 \times 10^{-6} \mathrm{ng} / \mu \mathrm{L}$ via NanoDrop 2000 Spectrophotometer (Thermo Scientific), were used to run an amplification plot and standard curve to determine the sensitivity and specificity of the qPCR assay (Figure 1). The H. enhydrae genome size of $1.6 \mathrm{mb}$ was used to calculate the copy number (URI Genomics Sequencing Center, 2004).

TABLE 1 | Number of enrolled sea otters and total samples based on gastric sampling type.

\begin{tabular}{lcc}
\hline Gastric sampling type & $\begin{array}{c}\text { Enrolled } \\
\text { sea otters }\end{array}$ & $\begin{array}{c}\text { Total gastric } \\
\text { samples }\end{array}$ \\
\hline $\begin{array}{l}\text { Collected fresh at necropsy, } \\
\text { frozen immediately }\end{array}$ & 46 & 92 \\
$\begin{array}{l}\text { Formalin-fixed paraffin } \\
\text { embedded blocks }\end{array}$ & 45 & 59 \\
Gross necropsy data & 41 & 82 \\
Histology analyses & 37 & 57
\end{tabular}

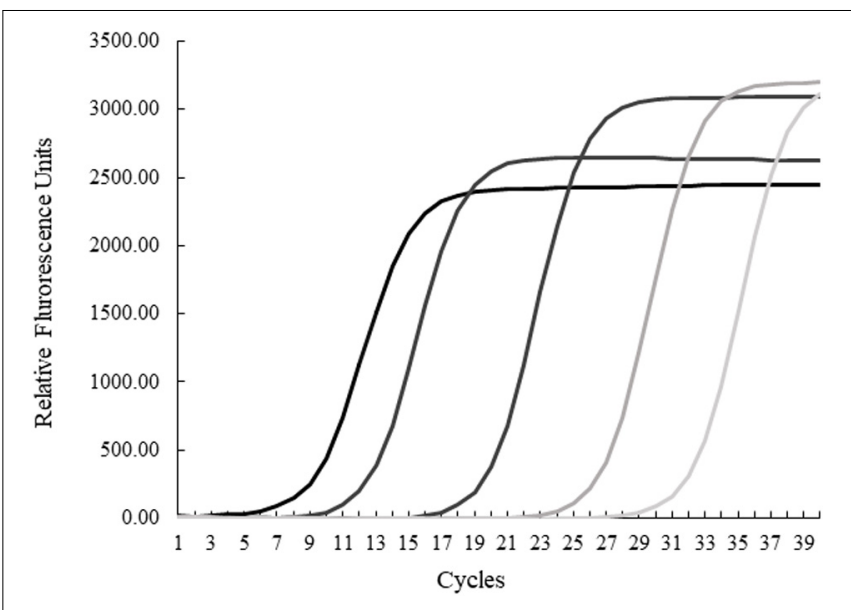

FIGURE 1 | Quantitative PCR results for serial dilutions of Helicobacter enhydrae genomic DNA. Amplification plots from left to right were generated from $89,8.9,8.9 \times 10^{-2}, 8.9 \times 10^{-4}$, and $8.9 \times 10^{-6} \mathrm{ng} / \mu \mathrm{L}$.

\section{Statistical Analyses}

Associations between sea otter gastric Helicobacter detection and demographic, gross postmortem, and histologic variables were assessed using statistical software JMP Pro 15.0 (SAS Institute Inc., United States). Similar relationships were evaluated for gastric pathology. The Fisher's exact test evaluated possible associations between Helicobacter PCR detection and gastric ulcers, as well as demographic, gross postmortem, and histology data. The significance level was set at $\alpha=0.05$, such that $P<0.05$ indicated a statistically significant difference.

\section{Histology}

Histological evaluations performed by lead author (F. Batac, MS) were reviewed by a veterinary pathologist (M. Miller, DVM, Ph.D., MS). Current human and sea otter gastric histology grading systems were reviewed and referenced in conducting sea otter histology evaluations (Supplementary Table S3). H\&E stained slides were used to evaluate the fixed gastric body and pylorus for features including erosions, ulcers, melena, gastritis, inflammatory cell type (neutrophilic or lymphoplasmacytic), and detection of suspect Helicobacter-like organisms (Supplementary Table S4).

\section{H. enhydrae Culture and ETEST ${ }^{\circledR}$ Antimicrobial Sensitivity Testing}

Helicobacter enhydrae MIT 01-6242 from Shen et al. (2017) was used for the antimicrobial sensitivity testing. Southern sea otter Helicobacter isolates MIT 01-5923 and MIT 01-5924 from Harper et al. (2003) were unavailable. Helicobacter enhydrae MIT 016242 was grown on solid media consisting of Columbia agar with $5 \%$ defibrinated horse blood (CHBA; Hemostat Laboratories) containing $10 \mu \mathrm{g} / \mathrm{mL}$ vancomycin, $50 \mu \mathrm{g} / \mathrm{mL}$ cycloheximide, $5 \mu \mathrm{g} / \mathrm{mL}$ cefsulodin, and 2.5 units/mL polymyxin $\mathrm{B}$, or liquid media containing Brucella broth with $10 \%$ heat-inactivated fetal bovine serum (BB10). For either growth mode, H. enhydrae was cultured at $37^{\circ} \mathrm{C}$ under microaerobic conditions $\left(10 \% \mathrm{CO}_{2}\right.$ and 
$5 \% \mathrm{O}_{2}$, balance $\mathrm{N}_{2}$ ). For the antimicrobial sensitivity testing, H. enhydrae was cultured on solid CHBA media, with subculture and passage to fresh plates every 3 days for 6 days. For the BB10 overnight incubation, a small amount of the plate-grown sample was transferred to the liquid. After overnight growth with shaking at $220 \mathrm{rpm}$, the absorbance $\left(\mathrm{OD}_{600}\right)$ was determined and cultures were used when the absorbance was between 0.199 and 0.785 . Then, $100 \mu \mathrm{L}$ of this broth was spread evenly onto separate CHBA plates. After spreading, the ETEST ${ }^{\circledR}$ strips (BioMérieux, each impregnated with a separate antibiotic), were placed on the surface of individual plates, and the plates were incubated as above. The zones of bacterial growth inhibition around the ETEST ${ }^{\circledR}$ strips were recorded visually and photographically following 2 days of incubation. The antibiotics tested in the study were amoxicillin, clarithromycin, chloramphenicol, kanamycin, nalidixic acid, and tetracycline.

\section{RESULTS}

\section{Helicobacter spp. Is Frequently Detected in Frozen Sea Otter Gastric Tissue}

We first examined our set of 92 frozen gastric tissue samples (body and pylorus) from 46 southern sea otters using qPCR to quantify the amount of Helicobacter DNA. We first ran an amplification plot and standard curve with purified $H$. enhydrae DNA (Figure 1). With this approach, we could detect $H$. enhydrae DNA concentrations as low as $8 \times 10^{-6} \mathrm{ng} / \mu \mathrm{L}$ and a qPCR assay sensitivity of 5 copies of Helicobacter DNA. These samples were considered Helicobacter qPCR-positive, while samples below this detection were marked as Helicobacter qPCR-negative. Of the 46 sea otters, 39 (85\%) had at least one positive tissue. By tissue, $83 \%$ of gastric pylorus (38/46) and 65\% of gastric body (30/46) samples were Helicobacter qPCR-positive (Figure 2). Among sea otters

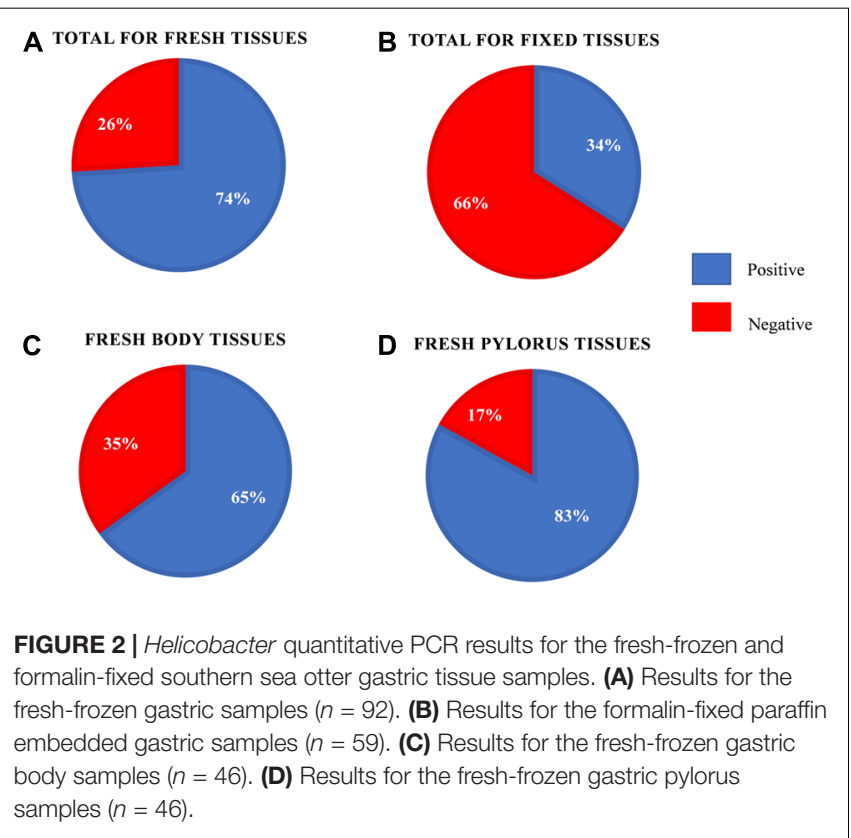

that were qPCR-positive, nearly three-quarters had Helicobacter DNA detected in both the gastric body and pylorus (29/39), while a quarter had Helicobacter DNA detected in only one of the two anatomical locations (10/39). Overall, these data show that majority of sea otters in this study had Helicobacter DNA in their stomachs, with more sea otters showing positive gastric pyloric samples than gastric body ones.

\section{Formalin-Fixed Tissues Underrepresent Helicobacter Status}

We next asked how formalin-fixed paraffin-embedded gastric tissue samples, from the same otters as those analyzed above, would compare for Helicobacter spp. detection. We were curious about this question because laboratories often have preserved tissue that could be used for similar analyses. Our tissues had been preserved in $10 \%$ buffered formalin for varying lengths of time (2 days to 2-3 weeks) prior to paraffin-embedding, and the paraffin-embedded samples were used for our analysis. qPCR of DNA extracted from these fixed tissues found that only $40 \%$ (18/45, fixed samples unavailable for one otter) scored positive for Helicobacter DNA. The fixed samples produced a mean Cq that was 4.2-4.7 higher than frozen samples, resulting in many of them being called as Helicobacter qPCR-negative (Figure 3). Both the gastric body and pylorus fixed samples yielded much lower Helicobacter detection than did frozen tissue. These results suggested that sea otter Helicobacter spp. qPCR testing of frozen gastric tissue was a more sensitive method than testing fixed gastric tissues.

\section{Positive Association Between Helicobacter spp. Detection and Gastric Ulcers in Sea Otters}

To investigate possible associations between Helicobacter spp. detection and gastric pathology, we evaluated a subset of 82 frozen gastric body and pylorus samples from 41 sea otters for which gross gastric evaluations were included in the postmortem examination (Table 1). Fifty-one percent (21/41) of necropsied sea otters had gastric ulcers observed in the

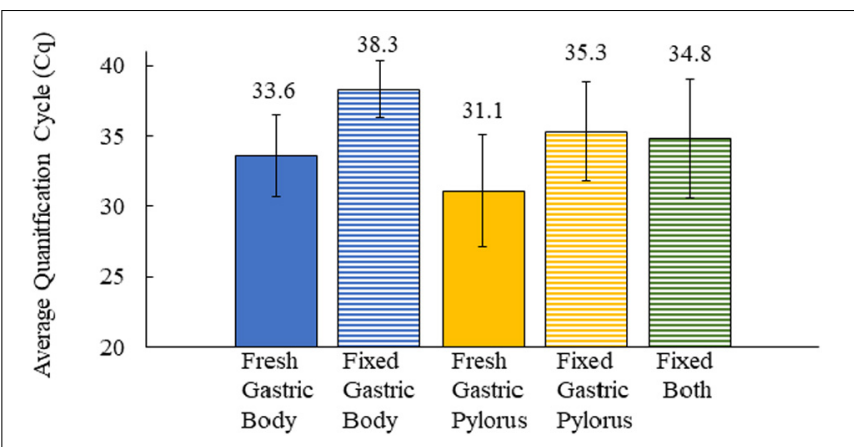

FIGURE 3 | Comparison of the average quantification cycle for sea otter gastric tissues as fresh-frozen (fresh) $(n=92)$ and formalin-fixed, paraffin-embedded (fixed) $(n=59)$ samples. Fixed both = gastric body and pylorus in same paraffin-embedded sample. Error bars = standard deviation. 
gastric body and/or pylorus, with 45\% (37/82) of frozen gastric samples displaying gastric ulcers. Among frozen gastric samples that had ulcers, nearly $90 \%$ (33/37) were also Helicobacter qPCR-positive (Figure 4). Helicobacter qPCR-positive gastric samples were significantly associated with gastric ulceration (2-sided Fisher's exact test, $P=0.005)$. Among the 41 sea otters with gross gastric evaluations at necropsy, the proportion of otters that were Helicobacter qPCR-positive was higher among those with gastric ulcerations (2-sided Fisher's exact test, $P=0.04$ ), and in fact, 6 of the 7 Helicobacter qPCRnegative individuals had no visible gastric ulcers. Collectively, these findings suggest that Helicobacter qPCR-positive sea otters were more likely to have gastric ulcers than Helicobacter qPCRnegative animals (Figure 4).

No associations were found between Helicobacter qPCR detection and age, sex, melena, shark trauma COD, or parasitic CODs (e.g., acanthocephalan or protozoal infections) (Fisher's exact test, $P>0.1$ ), although small sample sizes limited our ability to detect differences (Supplementary Table S1).

\section{Histologic Assessments of Ulcers Did Not Reflect Gross Postmortem \\ Assessments}

We determined whether histological samples could accurately reflect grossly apparent gastric ulcer status in sea otters (Supplementary Table S3). H\&E-stained histology slides determined 25\% (14/57) gastric ulcer presence as compared to gross postmortem examination which reported 45\% (37/82) ulcer presence (Supplementary Tables S1, S4). A histological determination of gastritis or melena were not statistically associated with qPCR Helicobacter detection (Fisher's exact test, $P=0.3$ ), suggesting that these may not be useful indicators of possible Helicobacter infection. This result may be partially explained by our small sample size for histology assessment (Table 1), due in part to autolysis and varying gastric tissue sizes on the microscopic slides. Additionally, gastric histology is performed on a small sample of tissue, which may not accurately

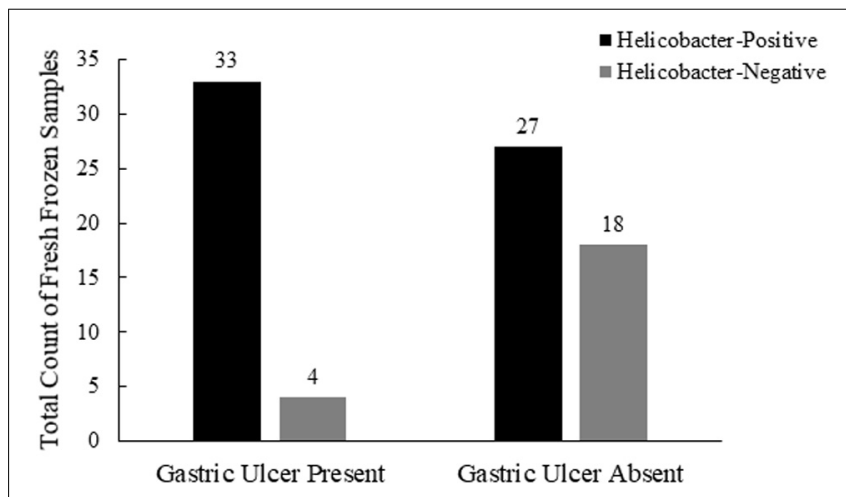

FIGURE 4 | Comparison of southern sea otter Helicobacter spp. infections and postmortem coding of gastric ulcers in the stomach body and pylorus ( $n=82,10$ samples with unknown ulcers removed from this analysis). represent all pathology present in the organ itself (i.e., focal gastric ulcers may be missed).

\section{Select Histologic Findings for Individual Helicobacter qPCR-Positive Sea Otters}

While different histologic attributes were graded, the main characteristics assessed were gastric erosions/ulcers, gastritis, and melena (Supplementary Table S4). Figure 5 shows severe pyloric gastric ulcers from a Helicobacter qPCR-positive subadult female. Severe pyloric gastric mucosal ulcers with perilesional mucosal hemorrhage were confirmed at gross necropsy, based on a dark brown to black appearance due to the action of gastric acid $\mathrm{pH}$ on blood (Figure 5A). Histopathology of these lesions revealed mucosal coagulation necrosis associated with thrombosis of underlying blood vessels and perilesional hemorrhage (Figure 5B). This pattern of deep vascular thrombosis leading to an acute wedge-shaped mucosal infarct is more typical of stress, hypovolemia, shock, etc., and not usually Helicobacter-associated.

Chronic inflammation would be more characteristic for Helicobacter-associated lesions. Figure $\mathbf{6}$ shows pyloric gastric mucosal lesions from a Helicobacter qPCR-positive adult male. Grossly, this otter had severe pyloric gastric mucosal ulcers, severe perilesional mucosal hemorrhage, and melena (Figure 6A). Histopathology revealed focal expansion of pyloric lamina propria by nonsuppurative inflammation and mild stromal collapse (Figure 6B).

\section{Antimicrobial Sensitivity Tests on H. enhydrae Reveal Sensitivity to Clarithromycin and Tetracycline in vitro}

We investigated the antimicrobial sensitivity of southern sea otter H. enhydrae strain MIT 01-6242 (Shen et al., 2017). We chose ETEST $^{\circledR}$ gradient strips with antibiotics commonly used to treat $H$. pylori or were previously tested against this $H$. enhydrae strain to assess minimum inhibitory concentration

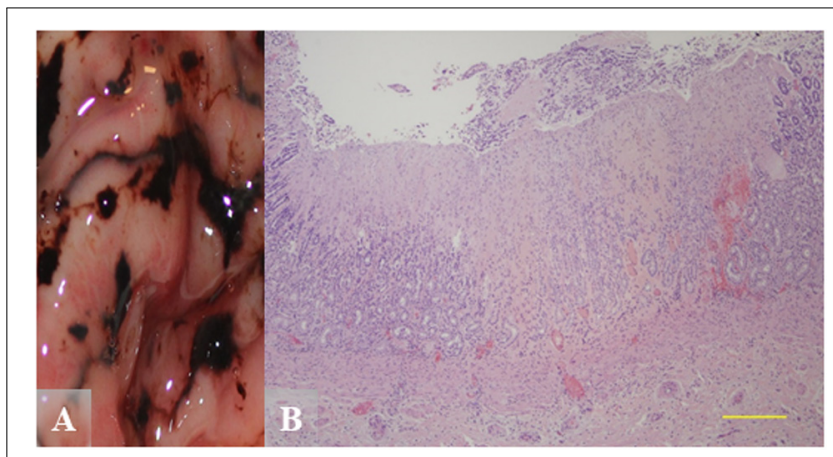

FIGURE 5 | Gross and hematoxylin and eosin (H\&E) images from a Helicobacter qPCR-positive, gastric ulcer-positive subadult female southern sea otter. (A) Gross image of severe pyloric gastric mucosal ulcers with perilesional mucosal hemorrhage. (B) Microscopic view of a pyloric mucosal infarct from the same animal as in (A). Focally extensive mucosal coagulation necrosis is associated with thrombosis of underlying blood vessels and perilesional hemorrhage. Scale bar $=500 \mu \mathrm{m}$. 


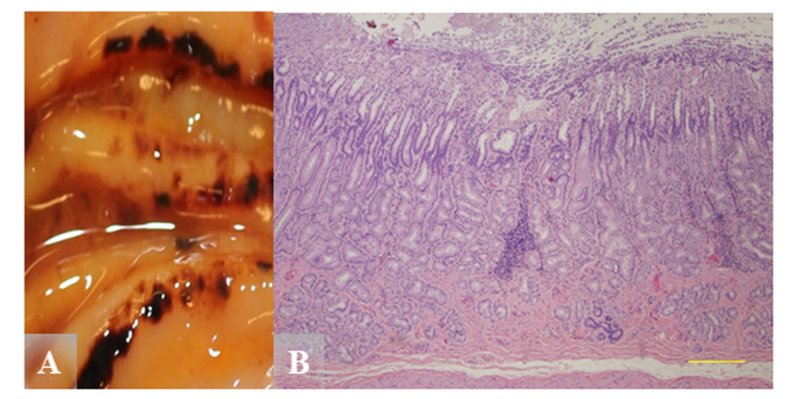

FIGURE 6 | Gross and hematoxylin and eosin (H\&E) images from a Helicobacter qPCR-positive, gastric ulcer-positive adult male southern sea otter. (A) Severe pyloric mucosal erosions and ulcers with perilesional mucosal hemorrhage and melena. Most of the lesions are aligned along the tips and edges of rugal folds. (B) Microscopic view of pylorus showing focal expansion of pyloric lamina propria by nonsuppurative inflammation, in association with mild stromal collapse. H\&E, Scale bar $=500 \mu \mathrm{m}$.

TABLE 2 | The minimum inhibitory concentrations (MICs) of Helicobacter enhydrae sp. nov (MIT 01-6242) against antimicrobial agents targeted toward bacteria like $H$. pylori.

\section{Antimicrobial Agent}

Amoxicillin (AC)

Clarithromycin $(\mathrm{CH})$

Chloramphenicol (CL)

Kanamycin (KM)

Nalidixic acid (NA)

Tetracycline (TC)

The ETEST ${ }^{\circledR}$ predefined antibiotic gradient range is from 0.016 to $256 \mu \mathrm{g} / \mathrm{mL}$.

(MIC). ETEST ${ }^{\circledR}$ gradient strips have comparable results for the most part to other antimicrobial sensitivity tests, such as agar dilution, broth microdilution, and disk diffusion (Glupczynski et al., 1991; Hachem et al., 1996; Miftahussurur et al., 2020). We assessed MICs for the following antibiotics: amoxicillin, clarithromycin, chloramphenicol, kanamycin, nalidixic acid, and tetracycline. These broad-spectrum antibiotics exhibited varying MICs (Table 2) based on their respective zones of inhibition of bacterial growth (Figure 7). Antibiotics effective at low dosages create a large "zone of inhibition" in vitro. Bacterial isolates that can withstand a high antibiotic dosage exhibit a smaller zone of inhibition around the ETEST ${ }^{\circledR}$ gradient strip and are described as more resistant. Clarithromycin and tetracycline, antibiotics effective against $H$. pylori as well as numerous grampositive and gram-negative bacteria (Peters and Clissold, 1992; Chopra and Roberts, 2001; Chey et al., 2017), exhibited the largest zones of inhibition with MICs between $\leq 0.016$ and $0.047 \mu \mathrm{g} / \mathrm{mL}$ (Table 2). In comparison, the MICs for clarithromycin and tetracycline against $H$. pylori isolates ranged from $<0.016$ to $0.064 \mu \mathrm{g} / \mathrm{mL}$ (Glupczynski et al., 1991; Hachem et al., 1996; Miftahussurur et al., 2020). Amoxicillin, chloramphenicol, kanamycin, and nalidixic acid were less effective antibiotics than clarithromycin and tetracycline, with MIC ranging from 0.5 to $16 \mu \mathrm{g} / \mathrm{mL}$ (Table 2).

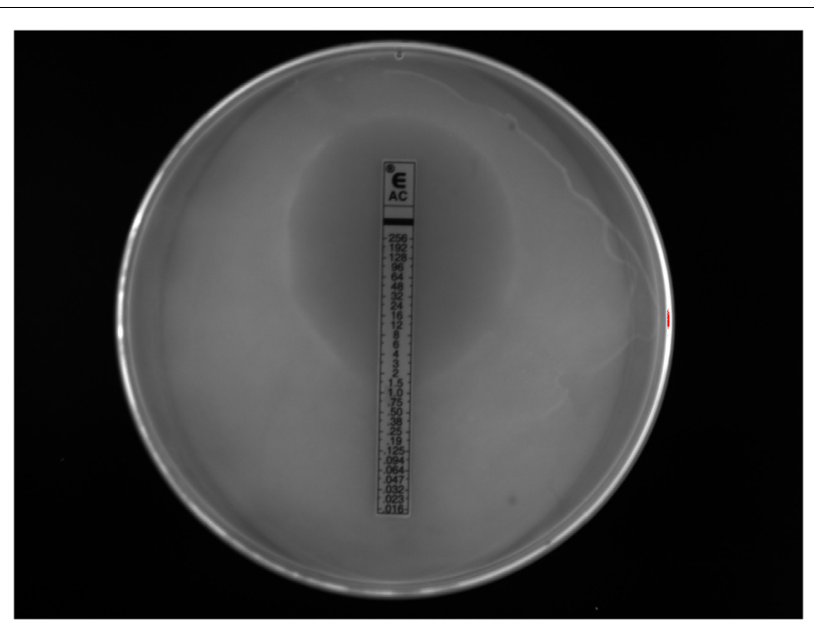

FIGURE 7 | A visible zone of Helicobacter enhydrae growth inhibition around an ETEST ${ }^{\circledR}$ amoxicillin (AC) gradient strip on $\mathrm{CHBA}$ media showed this trial with a minimum inhibitory concentration at $1.0 \mu \mathrm{g} / \mathrm{mL}$.

\section{DISCUSSION}

We found that $85 \%(39 / 46)$ of necropsied sea otters in our study between 2015 and 2017 were qPCR positive for Helicobacter DNA in fresh-frozen gastric tissues. Our reported Helicobacter prevalence in our sample population is higher than the 58\% reported in a prior study (Shen et al., 2017) that used conventional PCR. This may be because qPCR has higher sensitivity than conventional PCR. Our study and Shen et al. (2017) described higher Helicobacter detection in the gastric pylorus (83 and 45\%, respectively) than the gastric body (65 and 10\%, respectively). The gastric body glands all contain acid-secreting parietal cells, while in the pylorus/antrum, parietal cells are either present in only half of the glands in humans or are absent in rodents (Willet and Mills, 2016). The antrum/pylorus is also the preferred Helicobacter colonization site for ferrets, with higher bacterial abundance and more significant gastritis in this region (Vargas et al., 1991; Yu et al., 1995; Fox et al., 1997). We tested matching formalin-fixed tissues to investigate whether we could use archived formalinfixed gastric tissues to determine Helicobacter DNA presence. Fixed tissue analysis underrepresented Helicobacter status and produced an average overall Cq of 4.2-4.7 higher than their frozen counterparts, and thus, more fixed tissues were falsely Helicobacter qPCR negative. The differing $\mathrm{Cq}$ values may be due to the creation of abasic sites and DNA fragmentation by formalin fixatives, which can lower DNA integrity and quantity, negatively affecting its ability to be amplified by PCR as shown in other tissues (Do and Dobrovic, 2015). Our study confirms that this effect is true in sea otter tissue samples as well. Due to the differing qPCR Cq values of fixed tissues, the study did not utilize archival fixed southern sea otter gastric tissues dating back to the mid-1990s, which would have increased the sample size and provided a retrospective look into Helicobacter prevalence. 
Southern sea otters were previously known to be infected with $H$. enhydrae sp. nov., which is related to the pathogenic species $H$. mustelae from ferrets (Shen et al., 2017). The novel species contained virulence factors, such as two copies of flagellin $(f l a A)$ and chaperone protein DnaJ (dnaJ), that have aided pathogenicity in the related $H$. mustelae (Shen et al., 2017). In addition, gastric ulcers were recognized as a common pathologic lesion in sea otters, often contributing to morbidity and mortality (Miller et al., 2017). However, associations between $H$. enhydrae presence and sea otter gastric ulcers were previously undetermined. In this study, we found that Helicobacter qPCR detection was common among the 46 sea otters in our study and had a statistically significant association with gastric ulcers (Figure 4).

An extensively studied mustelid with Helicobacter are captive domestic ferrets, which are highly colonized by $H$. mustelae (Fox et al., 1990; Forester et al., 2000). Previous analysis found that $100 \%$ of 67 sampled ferrets from United States research facilities and veterinary practices in a 2-year span were $H$. mustelae positive via culture from gastric biopsies (Fox et al., 1991a). This prevalence is higher than we reported for $H$. enhydrae. Helicobacter mustelae is known to inhibit acid secretion by parietal cells, increasing gastric $\mathrm{pH}$ and creating a favorable environment for bacterial proliferation (Fox et al., 1991b; Vargas et al., 1991), possibly explaining the high levels of ferret infection. Helicobacter mustelae is the only non-pylori Helicobacter reported to cause gastric ulcers and cancer in its native host (O'Toole et al., 2010), and lesion development was confirmed through fulfillment of Koch's postulates (Fox et al., 1991b).

Gastric ulcer etiology is likely multifactorial in wild and captive sea otters, including a multitude of stressors such as oil spill contamination, captivity, trauma, hypovolemia, shock, and concurrent disease (Lipscomb et al., 1993; Williams and Davis, 1995; Reimer and Lipscomb, 1998). Stress ulcers are defined as multiple superficial erosions of the gastric mucosa. Stress ulcers are considered independent of Helicobacter spp. infection and arise in humans from damage to the mucosal barrier that is secondary to some other systemic stress, refluxed bile, and/or high gastric acid secretion (Goldman and Rosoff, 1968; Haglund, 1990). Stress elevates glucocorticoids that can increase vasoconstriction and promote clotting, and thus ulcer development (Loughlin, 1994). Glucocorticoids also have potent anti-inflammatory and immunosuppressive effects (Munck et al., 1984; Sapolsky et al., 2000), potentially allowing pathogens like Helicobacter to proliferate and cause gastric lesions. Thus, stress gastric ulcers and Helicobacter-associated gastric ulcers may not be mutually exclusive in sea otters.

Gastric ulcers have been reported in necropsied southern sea otters since the 1960s, and captive sea otters with suspected gastric lesions have been treated medically with various approaches (Mattison and Hubbard, 1969; Williams and Davis, 1995). During the 1989 Exxon Valdez Oil Spill in Alaska, oiled northern sea otters (Enhydra lutris kenyoni) with suspected gastrointestinal ulcers were treated via stress reduction (i.e., reduced human interactions) and the antacid cimetidine (Williams and Davis, 1995). Cimetidine may be non-ideal, since it interacts with cytochrome p450 and may have adverse effects on hepatic petroleum hydrocarbon detoxification (Williams and Davis, 1995). Other treatment options include histamine $\mathrm{H}_{2}$-receptor antagonists (e.g., famotidine) and an antibiotic (e.g., procaine penicillin, amoxicillin, or metronidazole), which are routinely given to sick or injured southern sea otters in rehabilitation to prevent gastric ulcers (Dr. Michael Murray-Monterey Bay Aquarium, pers. comm.). Antibiotics and gastric relief medications are typically used in tandem to treat humans and ferrets with Helicobacter infections and gastric illnesses. Studies investigating medical treatments for ferret $H$. mustelae determined that a combination of drugs was the most effective mode of bacterial eradication, including a triple therapy consisting of amoxicillin, metronidazole, and bismuth subsalicylate (Otto et al., 1990). Bismuth subsalicylate triple therapy with amoxicillin and metronidazole cleared current $H$. mustelae infections and decreased gastritis in 100\% (9/9) of ferrets tested (Czinn et al., 1996). Triple therapies are commonly used to treat human $H$. pylori infections with an increasing shift to quadruple therapy due to antibiotic resistance (Graham and Fischbach, 2011). Similar triple therapies as those used for $H$. pylori and $H$. mustelae could be explored for treating $H$. enhydrae.

A prior study reported $H$. enhydrae sensitivity toward two antibiotics, cephalothin and nalidixic acid, at $30 \mu \mathrm{g}$ each (Shen et al., 2017). Our findings for nalidixic acid agree with the previous reports, but we did not test cephalothin due to discontinuation of the ETEST ${ }^{\circledR}$ strips by the manufacturer. We expanded the antibiotic profile to evaluate the best antibiotic choices and dosages that could be used against $H$. enhydrae. Clarithromycin and tetracycline were effective at the lowest dose. Since procaine penicillin and metronidazole had been used on aquaria sea otters (Dr. Michael Murray-Monterey Bay Aquarium, pers. comm.), it would be beneficial if additional studies determined their MICs against $H$. enhydrae.

Although our work has advanced our understanding of Helicobacter spp. in sea otters, some unanswered questions remain. It is unknown if $H$. enhydrae has multiple strains with varying virulence and antibiotic sensitivities, like H. pylori. There have been no in vivo studies on $H$. enhydrae, and murine models could be useful for experimental validation of whether or not this bacterium causes gastric pathogenesis. Fecaloral transmission of Helicobacter spp. through poor sanitation and water quality is a human health concern and is a likely route of exposure for sea otters in close quarters in aquaria and/or rehabilitation. Helicobacter spp. have recently been isolated and sequenced from 12/22 fecal samples of marine zoo mammals in Belgium (De Witte et al., 2018). PCR analysis of sea otter fecal matter and survival of $H$. enhydrae in seawater will help elucidate whether this is a potential route of transmission for this species. An immunohistochemistry (IHC) stain for $H$. enhydrae would expedite future diagnosis. We used a $H$. pylori IHC stain on known positive and negative $H$. enhydrae cases from Shen et al. (2017) but results were inconclusive. 
In summary, our results provide evidence of Helicobacter DNA in gastric samples of southern sea otters and a positive association between Helicobacter detection and gastric ulcers. Fresh frozen gastric tissue, rather than formalin-fixed tissue, is the recommended sample type for qPCR detection of Helicobacter spp. in sea otters. Furthermore, these bacteria are sensitive to antibiotics in vitro, and if future studies suggest clinical intervention is warranted, this information can help guide treatment choices. These findings provide evidence that Helicobacter spp. may be an important component of sea otter gastric health and disease and support the need for additional research to characterize the population impact on this threatened marine species.

\section{DATA AVAILABILITY STATEMENT}

All datasets presented in this study are included in the article/Supplementary Material.

\section{ETHICS STATEMENT}

All work was performed in accordance with Section 109(h) of U.S. Marine Mammal Protection Act (MMPA), U.S. Fish and Wildlife Service (Service) regulations implementing the MMPA at 50 CFR 18.22(a), and in accordance with Service regulations implementing the U.S. Endangered Species Act at 50 CFR 17.21(c)(3).

\section{AUTHOR CONTRIBUTIONS}

FB designed the research project, conducted the experiments, and wrote the manuscript. FB and MEM conducted the statistical analyses. MAM provided sea otter gastric samples, oversaw histology slide interpretation, and verified histology results. ZS and JF provided $H$. enhydrae isolates and unstained

\section{REFERENCES}

Batchelder, M., Fox, J. G., Hayward, A., Yan, L., Shames, B., Murphy, J. C., et al. (1996). Natural and experimental Helicobacter mustelae reinfection following successful antimicrobial eradication in ferrets. Helicobacter 1, 34-42. doi: 10. 1111/j.1523-5378.1996.tb00006.x

Chey, W. D., Leontiadis, G. I., Howden, C. W., and Moss, S. F. (2017). ACG clinical guideline: treatment of Helicobacter pylori infection. Am. J. Gastroenterol. 112, 212-239. doi: 10.1038/ajg.2016.563

Chopra, I., and Roberts, M. (2001). Tetracycline antibiotics: mode of action, applications, molecular biology, and epidemiology of bacterial resistance. Microbiol. Mol. Biol. Rev. 65, 232-260. doi: 10.1128/MMBR.65.2.232-260.2001

Cover, T. L., and Blaser, M. J. (1996). Helicobacter pylori infection, a paradigm for chronic mucosal inflammation: pathogenesis and implications for eradication and prevention. Adv Intern Med. 41, 85-117.

Czinn, S. J., Bierman, J. C., Diters, R. W., Blanchard, T. G., and Leunk, R. D. (1996). Characterization and therapy for experimental infection by Helicobacter mustelae in ferrets. Helicobacter 1, 43-51. doi: 10.1111/j.1523-5378.1996. tb00007.x

De Witte, C., Lemmens, C., Flahou, B., De Laender, P., Bouts, T., Vercammen, F., et al. (2018). Presence of Helicobacter and Campylobacter species in faecal histology slides. KO provided E. coli isolates, access to research infrastructures, and guidance on experimental design. All authors reviewed, edited, and approved the manuscript.

\section{FUNDING}

This work was supported by funding from CDFW-MWVCRC, Department of Microbiology and Environmental Toxicology at UC Santa Cruz, California Sea Otter Fund, Oiled Wildlife Care Network Small Grant, Sea Otter Foundation and Trust Grant, The Friends of Seymour Marine Discovery Center's Student Research and Education Award, American Association of University Women Re-Entry Scholarship, and the Marilyn C. and Raymond E. Davis Memorial Scholarship. A Special Research Grant and Collaborative Research Matching Funds were awarded by the Committee on Research from UC Santa Cruz.

\section{ACKNOWLEDGMENTS}

We thank the staff and volunteers at CDFW-MWVCRC, U.S. Geological Survey, Monterey Bay Aquarium, and The Marine Mammal Center who assisted in the collection and examination of stranded sea otters off the California coastline. We also thank Vinh Tran, Laird Henkel, Dr. Michael Murray, Myra Finkelstein, and Donald R. Smith for support and guidance on the manuscript, and Erin Dodd, Colleen Young, Angelina Reed, Katherine Greenwald, Rebecca Griffey, Amber Villarreal, Kieran Collins, Christina Yang, Kevin Johnson, Shuai Hu, and Jashwin Sagoo for support and guidance with these experiments.

\section{SUPPLEMENTARY MATERIAL}

The Supplementary Material for this article can be found online at: https://www.frontiersin.org/articles/10.3389/fmars. 2020.00413/full\#supplementary-material

samples from zoo mammals. Vet. Microbiol. 219, 49-52. doi: 10.1016/j.vetmic. 2018.04.014

Do, H., and Dobrovic, A. (2015). Sequence artifacts in DNA from formalin-fixed tissues: causes and strategies for minimization. Clin. Chem. Wash 61, 64-71. doi: 10.1373/clinchem.2014.223040

Dudek, N. (2018). Diversity, Form, and Function Within the Marine Mammal Microbiota. Doctoral dissertation, UC Santa Cruz, Santa Cruz, CA.

Forester, N. T., Parton, K., Lumsden, J. S., and O’Toole, P. W. (2000). Isolation of Helicobacter mustelae from ferrets in New Zealand. N Z Vet J. 48, 65-69. doi: 10.1080/00480169.2000.36161

Fox, J. G., Correa, P., Taylor, N. S., Lee, A., Otto, G., Murphy, J. C., et al. (1990). Helicobacter mustelae-associated gastritis in ferrets. Gastroenterology 99, 352-361. doi: 10.1016/0016-5085(90)91016-Y

Fox, J. G., Dangler, C. A., Sager, W., Borkowski, R., and Gliatto, J. M. (1997). Helicobacter mustelae-associated gastric adenocarcinoma in ferrets (Mustela putorius furo). Vet. Pathol. 34, 225-229. doi: 10.1177/0300985897034 00308

Fox, J. G., Otto, G., Murphy, J. C., Taylor, N. S., and Lee, A. (1991a). Gastric colonization of the ferret with Helicobacter species: natural and experimental infections. Rev. Infect. Dis. 13, S671-S680. doi: 10.1093/clinids/13.Supplement_ 8.S671 
Fox, J. G., Otto, G., Taylor, N. S., Rosenblad, W., and Murphy, J. C. (1991b). Helicobacter mustelae-induced gastritis and elevated gastric $\mathrm{pH}$ in the ferret (Mustela putorius furo). Infect. Immun. 59, 1875-1880. doi: 10.1128/IAI.59. 6.1875-1880.1991

Fox, J. G., Taylor, N. S., Edmonds, P., and Brenner, D. J. (1988). Campylobacter pylori subsp. mustelae subsp. nov. isolated from the gastric mucosa of ferrets (Mustela putorius furo), and an emended description of Campylobacter pylori. Int. J. Syst. Evol. Micr. 38, 367-370. doi: 10.1099/00207713-384-367

Glupczynski, Y., Labbe, M., Hansen, W., Crokaert, F., and Yourassowsky, E. (1991). Evaluation of the E test for quantitative antimicrobial susceptibility testing of Helicobacter pylori. J. Clin. Microbiol. 29, 2072-2075. doi: 10.1128/JCM.29.9. 2072-2075.1991

Goldman, H., and Rosoff, C. B. (1968). Pathogenesis of acute gastric stress ulcers. Am. J. Pathol. 52, 227-244.

Graham, D. Y., and Fischbach, L. A. (2011). Empiric therapies for Helicobacter pylori infections. CMAJ Can. Med. Assoc. J. 183, E506-E508. doi: 10.1503/cmaj. 101460

Hachem, C. Y., Clarridge, J. E., Reddy, R., Flamm, R., Evans, D. G., Tanaka, S. K., et al. (1996). Antimicrobial susceptibility testing of Helicobacter pylori comparison of E-test, broth microdilution, and disk diffusion for ampicillin, clarithromycin, and metronidazole. Diagn. Micr. Infect. Dis. 24, 37-41. doi: 10.1016/0732-8893(95)00252-9

Haglund, U. (1990). Stress ulcers. Scand. J. Gastro 25, 27-33. doi: 10.3109/ 00365529009093124

Harper, C. G., Feng, Y., Xu, S., Taylor, N. S., Kinsel, M., Dewhirst, F. E., et al. (2002). Helicobacter cetorum sp. nov., a urease-positive Helicobacter species isolated from dolphins and whales. J. Clin. Microbiol. 40, 4536-4543. doi: 10.1128/JCM. 40.12.4536-4543.2002

Harper, C. G., Xu, S., Rogers, A. B., Feng, Y., Shen, Z., Taylor, N. S., et al. (2003). Isolation and characterization of novel Helicobacter spp. from the gastric mucosa of harp seals Phoca groenlandica. Dis Aquat. Organ. 57, 1-9. doi: 10.3354/dao057001

Hatfield, B. B., Yee, J. L., Kenner, M. C., and Tomoleoni, J. A. (2019). California sea otter (Enhydra lutris nereis) census results, Spring 2019. U.S. Geol. Survey Data Ser. 1118 , 12. doi: $10.3133 /$ ds 1118

Iversen, J. A. (1972). Basal energy metabolism of mustelids. J. Comp. Physiol. 81, 341-344. doi: 10.1007/BF00697754

Kreuder, C., Miller, M. A., Jessup, D. A., Lowenstine, L. J., Harris, M. D., Ames, J. A., et al. (2003). Patterns of mortality in southern sea otters (Enhydra lutris nereis) from 1998-2001. J. Wildl. Dis. 39, 495-509. doi: 10.7589/0090-3558-39.3.495

Lipscomb, T. P., Harris, R. K., Moeller, R. B., Pletcher, J. M., Haebler, R. J., and Ballachey, B. E. (1993). Histopathologic lesions in sea otters exposed to crude oil. Vet. Pathol. 30, 1-11. doi: 10.1177/030098589303000101

Loughlin, T. R. (1994). in Marine Mammals and the Exxon Valdez, 1st Edn, ed. T. R. Loughlin (Cambridge, MA: Academic Press).

Mansour-Ghanaei, F., Samadi, A., Joukar, F., Fakheri, H. T., Hassanipour, S., Ashoobi, M. T., et al. (2019). Efficacy and tolerability of fourteen-day sequential quadruple regimen: pantoprazole, bismuth, amoxicillin, metronidazole and or furazolidone as first-line therapy for eradication of Helicobacter pylori: a randomized, double-blind clinical trial. EXCLI J. 18, 644-652. doi: 10.17179/ excli2019-1613

Marshall, B., and Warren, J. R. (1984). Unidentified curved bacilli in the stomach of patients with gastritis and peptic ulceration. Lancet. 323, 1311-1315. doi: 10.1016/S0140-6736(84)91816-6

Mattison, J. A., and Hubbard, R. C. (1969). Autopsy findings on thirteen sea otters (Enhydra lutris nereis) with correlations with captive animal feeding and behavior. Biol. Conserv. 60, 2761-2767.

Miftahussurur, M., Fauzia, K. A., Nusi, I. A., Setiawan, P. B., Syam, A. F., Waskito, L. A., et al. (2020). E-test versus agar dilution for antibiotic susceptibility testing of Helicobacter pylori: a comparison study. BMC Res. Notes 13:22. doi: 10.1186/ s13104-019-4877-9

Miller, M. A., Moriarty, M. E., Dodd, E. M., Burgess, T., Tinker, M. T., Batac, F. I., et al. (2017). The Dead do tell Tales: Investigating Sea Otter Mortality Patterns (1998-2012). Oakland, CA: California Coastal Conservancy, 156.

Morrison, P., Rosenmann, M., and Estes, J. A. (1974). Metabolism and thermoregulation in the sea otter. Physiol. Zool. 47, 218-229. doi: 10.1073/pnas. 1712629115
Munck, A., Guyre, P. M., and Holbrook, N. J. (1984). Physiological functions of glucocorticoids in stress and their relation to pharmacological actions. Endocr. Rev. 5, 25-44. doi: 10.1210/edrv-5-1-25

O’Toole, P. W., Snelling, W. J., Canchaya, C., Forde, B. M., Hardie, K. R., Josenhans, C., et al. (2010). Comparative genomics and proteomics of Helicobacter mustelae, an ulcerogenic and carcinogenic gastric pathogen. BMC Genomics 11:164. doi: 10.1186/1471-2164-11-164

Otto, G., Fox, J. G., Wu, P. Y., and Taylor, N. S. (1990). Eradication of Helicobacter mustelae from the ferret stomach: an animal model of Helicobacter (Campylobacter) pylori chemotherapy. Antimicrob. Agents Chemother. 34, 1232-1236. doi: 10.1128/AAC.34.6.1232

Peters, D. H., and Clissold, S. P. (1992). Clarithromycin - A review of its antimicrobial activity, pharmacokinetics properties and therapeutic potential. Int. Drugs 44, 117-164. doi: 10.2165/00003495-199244010-00009

Reimer, D. C., and Lipscomb, T. P. (1998). Malignant seminoma with metastasis and herpesvirus infection in a free-living sea otter (Enhydra lutris). J. Zoo. Wildl. Med. 29, 35-39.

Sapolsky, R. M., Romero, L. M., and Munck, A. U. (2000). How do glucocorticoids influence stress responses? Integrating permissive, suppressive, stimulatory, and preparative actions. Endocr. Rev. 21, 55-89. doi: 10.1210/edrv.21.1.0389

Shen, Z., Batac, F., Mannion, A., Miller, M. A., Bakthavatchalu, V., Ho, C., et al. (2017). Novel urease-negative Helicobacter sp. 'H. enhydrae sp. nov.' isolated from inflamed gastric tissue of southern sea otters. Dis. Aquat. Organ. 123, 1-11. doi: 10.3354/dao03082

Tarnawski, A., Tanoue, K., Santos, A. M., and Sarfeh, I. J. (1995). Cellular and molecular mechanisms of gastric ulcer healing. Is the quality of mucosal scar affected by treatment?. Scand. J. Gastroenterol. 30, 9-14. doi: 10.3109/ 00365529509090261

URI Genomics Sequencing Center (2004). Calculator for Determining the Number of Copies of a Template. Avaliable at: http://cels.uri.edu/gsc/cndna.html (assessed on March 10, 2020).

Vargas, M., Lee, A., Fox, J. G., and Cave, D. R. (1991). Inhibition of acid secretion from parietal cells by non-human-infecting Helicobacter species: a factor in colonization of gastric mucosa? Infect. Immun. 59, 3694-3699. doi: 10.1128/ IAI.59.10.3694-3699.1991

Willet, S. G., and Mills, J. C. (2016). Stomach organ and cell lineage differentiation: from embryogenesis to adult homeostasis. Cell Mol. Gastroenterol. Hepatol. 2, 546-559. doi: 10.1016/j.jcmgh.2016.05.006

Williams, B. H., Huntington, K. B., and Miller, M. A. (2018). "Mustelids," in Pathology of Wildlife and Zoo Animals, eds K. Terio, D. McAloose, and J. St. Jeger (Cambridge, MA: Academic Press), 287-304. doi: 10.1016/B978-0-12805306-5.00011-0

Williams, T. M., and Davis, R. W. (1995). "Rahabilitation of pregnant sea otters and females with newborn pups," in Emergency Care and Rehabilitation of Oiled Sea Otters: a Guide for Oil spills Involving Fur-Bearing Marine Mammals, eds T. M. Williams and R. W. Davis (Faribanks: University of Alaska Press).

Yeates, L. C., Williams, T. M., and Fink, T. L. (2007). Diving and foraging energetics of the smallest marine mammal, the sea otter (Enhydra lutris). J. Exp. Biol. 210, 1960-1970. doi: 10.1242/jeb.02767

Yu, J., Russell, M., Salomon, N., Murphy, J. C., Palley, L. S., and Fox, J. G. (1995). Effect of Helicobacter mustelae infection on ferret gastric epithelial cell proliferation. Carcinogenesis 16, 1927-1931. doi: 10.1093/carcin/16.8.1927

Zamani, M., Ebrahimtabar, F., Zamani, V., Miller, W. H., Alizadeh Navaei, R., Shokri Shirvani, J., et al. (2018). Systematic review with meta analysis: the worldwide prevalence of Helicobacter pylori infection. Aliment. Pharm. Therap. 47, 868-876. doi: 10.1111/apt.14561

Conflict of Interest: The authors declare that the research was conducted in the absence of any commercial or financial relationships that could be construed as a potential conflict of interest.

Copyright (c) 2020 Batac, Miller, Moriarty, Shen, Fox and Ottemann. This is an open-access article distributed under the terms of the Creative Commons Attribution License (CC BY). The use, distribution or reproduction in other forums is permitted, provided the original author(s) and the copyright owner(s) are credited and that the original publication in this journal is cited, in accordance with accepted academic practice. No use, distribution or reproduction is permitted which does not comply with these terms. 